ISSN 2616-7328 (Online), ISSN 2409-904X (Print)

Kitaêznavčì doslìdžennâ, 2021, No. 4, pp. 97-108

DOI: https://doi.org/10.51198/chinesest2021.04.097

UDC 811.581

\title{
A COMPARATIVE ANALYSIS OF GUO MORUO' AND MAO DUN'S IDEAS ON TRANSLATION
}

\author{
Wang Rong \\ Assistant Professor \\ School of Foreign Languages \\ Beijing University of Aeronautics and Astronautics \\ 37 Xueyuan Road, Haidian District, Beijing, P. R. China, 100191 \\ w200609@sina.com
}

In the $20^{\text {th }}$ century, two literary stars shone brightly on the Chinese literary scene, Guo Moruo and Mao Dun, who are among the six great literary figures of modern China. They were not only the authors of a large number of literary works, but also took an active part in the process of introducing foreign literature and renewing Chinese literature. For this reason, they both also proved to be excellent translators. This article explores Guo Moruo's and Mao Dun's ideas about translation through comparative analysis and reveals a number of similarities on five issues: the criteria of perfect translation, the quality control of translation, the problem of re-translation, the targeting of literary translation, and the critical view of literary translation. In doing so, they diverge in their understanding of the relationship between translation, creativity, and poetic translation. Finally, through a comparative study of their translation ideas, the contributions of Guo Moruo and Mao Dun to Chinese translation theory, the main ideas of the Chinese translation community in the $20^{\text {th }}$ century are shown, and some suggestions for further study and development of translation theory are formulated.

Keywords: Guo Moruo, Mao Dun, translation thoughts, comparative analysis.

\section{ПОРІВНЯЛЬНИЙ АНАЛІЗ ІДЕЙ ГО МОЖО ТА МАО ДУНЯ ПРО ПЕРЕКЛАД}

\section{Ван Жун}

У ХХ ст. на китайській літературній сцені яскраво сяяли дві літературні зірки - Го Можо і Мао Дунь, які є одними з шести великих літературних діячів сучасного Китаю. Вони були не лише авторами великої кількості літературних творів, а й брали активну участь у процесі знайомства з іноземною літературою та оновленням китайської літератури. 3 цієї причини вони обоє виявили себе і як чудові перекладачі. У цій статті на основі порівняльного аналізу досліджуються ідеї Го Можо та Мао Дуня про переклад, і виявляється низка схожих поглядів з п'яти питань, таких як: критерії ідеального перекладу, контроль якості перекладу, проблема повторного перекладу, цільова спрямованість літературного перекладу та критичний погляд на літературний переклад. При цьому вони розходяться у своєму розумінні взаємозв'язку між перекладом, творчістю

(C) 2021 Wang Rong; Published by the A. Yu. Krymskyi Institute of Oriental Studies, NAS of Ukraine and the Ukrainian Association of Sinologists on behalf of The Chinese Studies. This is an Open Access article distributed under the terms of the Creative Commons Attribution License (https://creativecommons.org/licenses/by-nc-nd/4.0/). 
та поетичним перекладом. Нарешті, завдяки порівняльному дослідженню їхніх перекладацьких ідей показано внесок Го Можо та Мао Дуня в китайську теорію перекладу, основні ідеї китайської перекладацької спільноти у ХX ст., а також сформульовано деякі пропозиції щодо подальшого вивчення та розвитку теорії перекладу.

Ключові слова: Го Можо, Мао Дунь, ідеї про переклад, порівняльний аналіз.

\section{СРАВНИТЕЛЬНЫЙ АНАЛИЗ ИДЕЙ ГО МОЖО И МАО ДУНЯ О ПЕРЕВОДЕ}

\section{Ван Жун}

В XX в. на китайской литературной сцене ярко сияли две литературные звезды Го Можо и Мао Дунь, которые являются одними из шести великих литературных деятелей современного Китая. Они были не только авторами большого числа литературных произведений, но и принимали активное участие в процессе знакомства с иностранной литературой и обновления китайской литературы. По этой причине они оба проявили себя и как прекрасные переводчики. В данной статье на основе сравнительного анализа исследуются идеи Го Можо и Мао Дуня о переводе, и обнаруживается ряд схожих взглядов по пяти вопросам, таким как: критерии идеального перевода, контроль качества перевода, проблема повторного перевода, целевая направленность литературного перевода и критический взгляд на литературный перевод. При этом они расходятся в своем понимании взаимосвязи между переводом, творчеством и поэтическим переводом. Наконец, благодаря сравнительному исследованию их переводческих идей показан вклад Го Можо и Мао Дуня в китайскую теорию перевода, основные идеи китайского переводческого сообщества в XX в., а также сформулированы некоторые предложения для дальнейшего изучения и развития теории перевода.

Ключевые слова: Го Можо, Мао Дунь, идеи о переводе, сравнительный анализ.

Го Можо (郭沫若, 1892-1978 гг.) и Мао Дунь (茅盾, 1896-1981 гг.) были двумя из шести великих литературных деятелей современного Китая. Оба писателя не только создали большое количество произведений, но и сделали блестящую карьеру как переводчики. В XX в. было осуществлено множество исследований идей Го Можо и Мао Дуня о переводе, которые были в основном сосредоточены на анализе техники и эстетики их переводов, но при этом лишь в нескольких работах предпринимались попытки осуществить сравнительный анализ работы этих двух великих переводчиков. Сравнительный анализ дает возможность более глубоко понять идеи о переводе Го Можо и Мао Дуня как выдающихся переводчиков и представителей литературных объединений «Общество созидания» (“创造社”, 1921-1929 гг.) и «Общество изучения литературы» (“文学研究会”, 1921-1932 гг.).

\section{1. Жизнь Го Можо и Мао Дуня}

Го Можо - писатель, поэт, историк, археолог и государственный деятель, первый президент Академии Наук КНР (1949-1978) - родился 16 ноября 1892 г. в семье народности хакка в м. Шавань уезда Лэшань провинции Сычуань. Го Можо в 1914 г. отправился в Японию, где в 1923 г. окончил медицинский факультет университета Кюсю (Япония). При этом здесь же у него возникает интерес к изучению иностранных языков и литературы, что закономерно приводит и к началу переводческой деятельности. Кроме того, с 1916 г. Го Можо начинает писать стихи. 
Го Можо внес огромный вклад в развитие китайской литературы, искусства, философии, истории, археологии, а также осуществил перевод на китайский язык теоретические работы марксизма-ленинизма и ряд произведений литературной классики. Безусловно, Го Можо - это фигура «энциклопедического» уровня, гигант китайской и мировой культуры XX в. Его богатое творчество имеет большое количество граней, однако в данной статье речь пойдет только о его деятельности в качестве переводчика.

С раннего детства Го Можо был погружен в китайскую традиционную культуру в целом и в конфуцианскую классику в частности. Го Можо родился в то время, когда на рубеже веков традиционное китайское общество переживало большие перемены. Здесь, в «старом» Китае, началось слияние восточной и западной культур, что создало идеальный климат для формирования целого поколения литературных деятелей. Вся интеллектуальная история, литературная карьера и переводческий путь Го Можо были тесно связаны с западной культурной мыслью. Именно через Японию он постигал и историю западной культуры и мысли от Древней Греции и эпохи Возрождения до современности.

Нет равных Го Можо среди современных литературоведов и переводчиков по широте охвата восточной и западной культуры, по глубине познания древнего и современного китайского языка, а также японского, английского, немецкого, латинского и др., по огромным достижениям в области перевода.

$\mathrm{B}$ «японский период» на протяжении двух десятилетий Го Можо проявил себя как талантливый литератор и переводчик. Это время можно разделить на четыре этапа: 1) токийский период (1914-1915 гг.), когда он учился на подготовительных курсах Первой средней школы; 2) период Окаяма (1915-1918 гг.), когда он три года учился в Шестой средней школе; 3) период Фукуока (1918-1923 гг.), когда он учился на медицинском факультете Императорского университета Кюсю; 4) период эмиграции (1928-1937 гг.), когда он занимался научными исследованиями и переводами шедевров зарубежной литературы.

Мао Дунь, китайский писатель и общественный деятель, получил классическое китайское и современное образование, и еще в детские годы проявил свой литературный талант. Мао Дунь учился на подготовительном отделении Пекинского университета, а с 1916 г. работал в издательстве в Шанхае. В 1920-1922 гг. он возглавлял журнал «Сяошо юэбао», а также в 1921 г. стал одним из основателей Общества изучения литературы. Вплоть до 1927 г. Мао Дунь работал как публицист, литературовед, критик и переводчик, знакомя китайского читателя с западноевропейской и русской литературой. Его перу принадлежат книги «Изучение персонажей» (1925 г.), «Китайская мифология» (1925 г.), «Введение в изучение прозы» (1928 г.) и др. Первым же его художественным произведением стала трилогия «Затмение» (1927-1928 гг.), состоящая из повестей «Разочарования», «Колебания» и «Поиски».

Мао Дунь был пионером современной прогрессивной культуры в Китае, революционным писателем, культурным и общественным деятелем с высокой репутацией в самом Китае и за рубежом, а также выдающимся переводчиком. За всю свою жизнь Мао Дунь перевел большое количество литературных произведений, а его книги были переведены на десятки языков, включая английский, французский, немецкий, русский, итальянский, испанский, японский, корейский, монгольский и др. Наследие Мао Дуня также многогранно, как и 
творчество Го Можо, и также принадлежит не только Китаю, но и всему миру. Особое внимание в данной статье уделяется его идеям о переводе, которые имеют непреходящее значение.

Становление и развитие теории перевода и переводческой мысли Мао Дуня, которые оказали колоссальное влияние на всех китайских переводчиков, можно разделить на два периода: 1) До и после Движения 4 мая, когда он вместе с Лу Синем (鲁迅, 1881-1936 гг.), Цюй Цюбо (瞿秋白, 1899-1935 гг.), Го Можо и другими деятелями культуры выступил с резкой критикой ошибочного стиля и тенденций, проявившихся в литературных переводах того времени, а также написал большое количество переводческих эссе, изложил свою теорию и идеи перевода. Мао Дунь опубликовал свои работы «Ответственность и усилия исследователей новой литературы» (1921 г.), «Рассуждения о методе перевода литературных книг» (1921 г.), «“Дословный перевод” и “пословный перевод”» (1922 г.) и другие, которые в то время вызывали горячие споры относительно дословного и вольного перевода; достоверности, доходчивости и изящества перевода ${ }^{1}$; перевода и творчества. 2) В период строительства нового Китая Мао Дунь всесторонне и систематически изложил свою теорию и идеи перевода в книге «Борьба за развитие литературного перевода и улучшение качества перевода» (1954 г.). Таким образом, наиболее значимый вклад Мао Дунем в теорию перевода был сделан не в период Движения 4 мая, а уже после создания в 1949 г. Китайской Народной Республики.

\section{2. Общие идеи Го Можо и Мао Дуня о переводе}

Мао Дунь первым в китайской теории перевода ввел понятие совершенного, романтического обаяния литературы (神韵 шэньюнь) для обозначения качества литературного перевода, который должен сохранить «дух» оригинала. В своей работе «Ответственность и усилия исследователей новой литературы» Мао Дунь писал: «Важнейшей художественной особенностью литературного произведения является совершенный характер этого произведения. Пессимистичную литературу мы не можем переводить как революционную; мистическую и декадентскую литературу мы не можем переводить как яркую и энергичную». То есть Мао Дунь требовал, чтобы перевод и оригинальный текст были похожи по ритму, по своему обаянию, и таким образом шэньюнь становится важным понятием литературной эстетики и теории перевода, что позже было развито в работах Го Можо, Чэнь Сиина (陈西漟, 1896-1970), Фу Лэя (傅雷, 1908-1966) и др. [李红英 2008, 127-128].

Вопрос о том, должна ли литература быть «искусством ради искусства» или «жизнью ради жизни», стал горячей темой дебатов в китайской литературной среде в 1920-е гг., что коснулось и вопросов перевода. Хотя Го Можо и Мао Дунь принадлежали к разным литературным группам, но между их идеями о переводе было много общего. Эти сходства в основном отражаются в пяти аспектах, таких как: критерии идеального перевода, контроль качества перевода, проблема повторного перевода, ориентация на цель литературного перевода и критический взгляд на литературный перевод.

1) Критерии идеального перевода. Го Можо считает, что идеальный перевод сохраняет слова, смысл и ритм, что было четко сформулировано в его работе «Мое мнение об идеальном переводе»: «Мы считаем, что идеальный перевод,

\footnotetext{
1 Три критерия перевода в изложении китайского философа Янь Фу (严复, 1854-1921 гг.)
} 
естественно, не допускает искажения слов и смысла оригинального текста, и особенно ритма оригинального текста. Должны быть учтены все слова оригинального текста, но нет необходимости переводить его слово за словом, первым или вторым, синтезом или анализом, и если смысл не нарушается, то перевод может быть свободно изменен ради рифмы» [罗新璋 2015, 403]. «Рифма» (韵 юнь) здесь соответствует традиционной китайской эстетической идее «основная мысль» (意境 иизин), которая китайским историком и филологом Ван Говэем (王国维, 1877-1927 гг.) также рассматривается как слова, исходящие из «рифмы». Это также лежит в основе идеи Го Можо о «рифмованном переводе». Стандарты и принципы перевода, предложенные Янь Фу, а именно достоверность, доходчивость и изящество, занимают незыблемое место в истории китайской переводческой мысли. По мнению Го Можо, «изящество» (雅 $я$ ) не означает высокий и глубокий уровень, не сводится к украшательству; «изящество» означает высокую литературную или художественную ценность. Понимание Го Можо «изящества» не ограничивалось лингвистическим уровнем, так как также выдвигались требования соответствия идее оригинального произведения, чтобы сохранялся ритм оригинального текста, чтобы помимо формы и содержания сохранялась гармония и единство ритма, чтобы получившийся перевод не только представлял интерес для читателя, но и позволял ему углубится в эстетический уровень и развивал более глубокое понимание «достоверности, доходчивости и изящества перевода». Как уже упоминалось выше, Мао Дунь первым в истории современного китайского перевода предложил термин шэньюнь, который он считал центральным для художественной характеристики литературного произведения. Он диалектически анализирует отношения между «формой» и шэньюнь при переводе поэзии. Из-за тесной связи между содержанием и формой, действительно, трудно осуществить перевод поэтического произведения так, чтобы сохранить одновременно форму и дух оригинала, и поэтому часто необходимо использовать более гибкие методы обращения с языком оригинала (включая словарный запас, ритм стиха, рифму и т. д.), чтобы передать чувства, фактуру и основную мысль оригинального стихотворения. Идеальный перевод должен сохранить очарование и передать художественную идею оригинального произведения. В своем докладе «Стремление к развитию литературного перевода и повышению качества перевода» Мао Дунь отметил, что «минимальное требование к переводу в целом должно заключаться, по крайней мере, в том, чтобы понятно и ясно передать содержание оригинального произведения. Однако для литературного перевода этого недостаточно. Литература - это искусство, созданное с помощью языка, и то, что мы требуем от литературы, - это не только понимание вещей и изложение сюжетов, но также и художественный контекст, который может привлечь читателя, то есть с помощью художественных образов, заставляющих читателя проникнуться мыслями и поступками героев книги. Перевод литературы - это способ передать художественное настроение оригинального произведения на другом языке, чтобы читатель при чтении перевода был бы так же вдохновлен, тронут красотой, как и при чтении оригинального произведения» [罗新璋 2015, 575]. По мнению Мао Дуня, идеальный перевод должен быть не только ясным, однозначным и верным содержанию, но и передающим и сохраняющим очарование оригинального произведения (шэньюнь) с помощью двух средств - правильного перевода слов и достижения духовного подобия, 
донося таким образом красоту до читателя. Будь то «изящный перевод» (风韵译 фэнъюньи) Го Можо или «обаяние литературы» (神韵 шэньюнь) Мао Дуня суть одна и та же. Они оба выходят за рамки простой буквальности и следуют традиционной китайской идеи «основной мысли», включая эстетические факторы в рамки идеального перевода и учитывая эстетический опыт и чувства читателя, что является существенным преодолением традиционного переводческого мышления.

2) Проверка качества перевода. Го Можо и Мао Дунь, как писатели и переводчики, также отличались высокой степенью патриотизма. Они оба занимались не только литературным творчеством, но также были активными участниками нового литературного движения в Китае, всегда интересовались целями развития китайского литературного сообщества, придавали большое значение качеству переводов и предлагали свои идеи по улучшению качества переводов и качества подготовки переводчиков. Для всего процесса перевода литературного произведения, от начала и до конца, необходимо постоянно учитывать оригинал, работу переводчика, восприятие читателя и переводческую критику. Реакцией на низкий уровень переводов и нетребовательность читателя к переводам стало выдвижение требований по улучшению качества переводов. Прежде всего, что касается переводчика, то необходимо пробудить в нем чувство ответственности. Для начала своей работы переводчик должен обладать необходимыми знаниями об оригинальном литературном произведении, его авторе и историческом контексте. Кроме того, переводчик должен обладать обширными лингвистическими знаниями, свободно владеть обоими языками и быть знатоком своей национальной литературы. Только при наличии этих основных качеств можно приступать к переводу. Переводить необходимо с высокой степенью ответственности, а не механически, иначе результат будет плачевным. Го Можо выступал против нездоровых тенденций того времени в переводческом сообществе Китая, и призывал повышать культуру и качество переводов, а не стремится к славе. С другой стороны, он считал, что нельзя недооценивать роль читателей в процессе оздоровления переводческого сообщества и соответственно повышения качества перевода. Го Можо настаивал на важности повышения уровня образования молодежи, в особенности изучения ею иностранных языков, что дает возможность чтения иностранной литературы в оригинале, а также призывал крупные книжные магазины Китая собирать больше шедевров из-за рубежа для обеспечения изучения иностранных языков новыми изданиями. Он считал, что таким образом удастся повысить уровень знаний читателей, которые, естественно, смогут сами отличать хороший перевод от плохого, и в результате некачественные переводы будут постепенно отсеиваться, а переводчики изо всех сил будут стараться улучшить свои профессиональные навыки для осуществления более качественных переводов, отвечающих потребностям читателей. Об усилиях Мао Дуня по улучшению качества перевода можно судить по его статье «Стремление к развитию художественного перевода и повышению качества перевода». Как и Го Можо, Мао Дунь также считает, что некачественные произведения не приносят пользы читателям. Он выдвинул к переводчикам несколько требований. Во-первых, переводчик должен иметь четкую цель и серьезное отношение к своей работе. Согласно Мао Дуню, при переводе литературного произведения 
переводчик должен учитывать, является ли оно «полезным и необходимым для читателя». Наши переводчики не должны «относиться к переводу как к наиболее удобной карьере, приносящей славу и богатство». Переводчик должен нести ответственность за литературное произведение, которое он переводит, и за читателя, неоднократно прорабатывая свой перевод для достижения наилучшего качества. Во-вторых, переводчик должен «владеть своим языком и языком оригинала» и «владеть пером и чернилами, чтобы передать стиль оригинала». При работе над конкретным переводом желательно, чтобы переводчик мог «читать иностранные тексты, думая и представляя их на языке этой страны». Он должен освободиться от особенностей языка оригинала, чтобы перевод был выполнен на своем национальном языке. В-третьих, переводчик должен иметь богатый жизненный опыт, ибо только тогда он сможет полностью понять жизнь, отраженную в оригинальном произведении. В-четвертых, переводчик должен провести тщательное научное исследование оригинального произведения, знать жизнь писателя. На основе марксистско-ленинской философии всесторонне проанализировать исторический период, общественные и жизненные обстоятельства, отраженные в произведении, а также идеи и стиль автора. В-пятых, переводчик должен иметь общую литературную подготовку. Более желательно, чтобы он был студентом литературного факультета, а также обладал необходимыми талантами. Переводчик должен поднять литературный перевод до уровня художественного творчества. Необходимо отметить, что Мао Дунь рассматривает критерии качества перевода более широко. Прежде всего, он указал на необходимость организованного и планового подхода к литературному переводу. Ранее публикация переведенного произведения во многом зависела от издателя как «покровителя», который зачастую выдвигал требования к переводчику, что негативно влияло на качество перевода. Кроме того, переводчики были разрознены, между ними не было связи, а деятельность издателей прежде всего определялась собственной материальной выгодой. Реагируя на эти негативные тенденции, Мао Дунь утверждал, что «литературный перевод должен планироваться и организовываться компетентными органами, а также всеми задействованными сторонами, под руководством партии и правительства, осуществляться методично и систематически» [罗新璋 2015, 572]. К тому же Мао Дунь предложил поднять литературный перевод до уровня художественного творчества. Наконец, тем, кто занимается литературным переводом, необходимо укреплять дух критики и самокритики, коллективной взаимопомощи, воспитывать новые переводческие кадры, повышать качество перевода, начиная с таких аспектов, как корректура и редакторская работа. Таким образом, Го Можо и Мао Дунь, основываясь на критическом подходе, выдвинули ряд требований к работе переводчиков, делая акцент на их ответственности, что было направлено на повышение качества переводов.

3) Повторный перевод. Го Можо категорически выступил против ограничений на повторный перевод того или иного литературного произведения. Он указывал на субъективность и индивидуальность переводчика, а также на различные требования читателей, и поэтому считал, что повторный перевод не только возможен, но и необходим. Мао Дунь также активно выступал за повторный перевод и считал, что сравнительное исследование двух переводов может в целом улучшить качество перевода. Он рассматривал повторный 
перевод как важное и даже обязательное средство обеспечения качества перевода [ 李红英 2008, 129]. Всегда существовало множество переводов различных произведений, и с течением времени появлялись новые переводы ранее переведенного произведения. Перевод и повторный перевод необходимы и обязательны во все времена не только для того, чтобы отражать изменения времени, но и для того, чтобы способствовать качеству перевода и расцвету переводческого сообщества. Мао Дунь считал, что истинные литературные шедевры обязательно необходимо переводить повторно. Го Можо и Мао Дунь, как писатели и переводчики, на практике осуществляли свои идеи относительно переводческой деятельности. «Изящный перевод» Го Можо или «обаяние литературы» Мао Дуня стали колоссальным шагом вперед в развитии теории перевода, которое стало учитывать эстетические аспекты и восприятие читателя. На основе понимания функции литературного перевода как средства содействия культурному обмену и развития национального языка Го Можо и Мао Дунь выразили свои взгляды на улучшение качества перевода и его критики, на необходимость повторного перевода, что в результате позитивно повлияло на развитие переводческого сообщества в Китае.

4) Целевая направленность художественного перевода. Перевод - это трансформация между двумя языками, объяснение идей и культуры другой страны через текст переводимого литературного произведения. Это имеет назидательное воздействие на читателя перевода, а также способствует развитию всех аспектов языка перевода. Го Можо утверждает, что благодаря переводу мы можем изучать состав и функционирование других языков, перенимать их сильные стороны и восполнять свои недостатки [罗新璋 2015,560 ]. Он считал, что художественная ценность хорошо переведенного литературного произведения сама по себе может раскрепостить умы нации и тем самым способствовать развитию Китая. Мао Дунь считал, что лексика и синтаксические особенности разных языков в процессе литературного перевода могут улучшить строгость китайского стиля письма. Он писал, что знакомство с западной литературой позволит познакомиться с современной прогрессивной мыслью [李红英2008, 127]. Для Мао Дуня знакомство с западной литературой в форме перевода должно было не только добавить сокровищ во дворец китайской литературы и искусства, но и просветить разум. Через литературу читатели могут знакомиться с чужими культурами, обогащать свою духовную жизнь, брать лучшее и совершенствовать собственные литературные произведения. Кроме того, Мао Дунь считал, что перевод является важной частью культурного обмена. Культуры разных народов и стран влияют на мышление людей, а также на творчество писателей. В процессе перевода нельзя игнорировать культурные факторы, а интерпретация иностранной литературы представляет собой обмен между китайской и западной культурой. Го Можо однажды сказал, что литература - это отражение реальной жизни. Поэтому благодаря литературному переводу можно понять обычаи и стремления людей разных стран, развивать творчество собственных писателей, учиться выражению жизни [罗新璋 2015, 560]. Го Можо, как и Мао Дунь, надеялся, что благодаря переводу иностранной литературы он сможет расширить кругозор своих соотечественников, понять местные обычаи разных стран и способствовать появлению новых литературных произведений в Китае. То есть Го Можо и Мао 
Дунь сходятся во мнении, что литературный перевод содействует развитию национального языка, а также способствует культурному обмену и созданию национальной литературы.

5) Критический взгляд на литературный перевод. Будь то литературное творчество или литературный перевод, критика всегда является важной частью этого процесса, мотивацией для улучшения и совершенствования произведения. Объективная и справедливая критика перевода способствует своевременному выявлению проблем и их устранению. Го Можо считает, что критика перевода должна осуществляться в основном с точки зрения мотивов перевода, уделяя внимание субъективности и индивидуальности человека. Признавая важность критики и самокритики в повышении качества переводческой работы, Мао Дунь выдвинул свои идеи о литературной переводческой критике в основном с точки зрения содержания переводческой критики. Указание на неправильный перевод слов и фраз - это необходимый шаг в процессе критики перевода, но на этом не следует останавливаться. Мао Дунь подчеркнул, что в критике больше внимания следует уделять сути перевода, пониманию переводчиком оригинального произведения, правильности переданного в переводе духа и стиля оригинального произведения, использованию языка в переводе, динамизму и уровню культуры переводчика [罗新璋2015, 579]. Хотя Го Можо и Мао Дунь формулируют свои идеи относительно критики перевода с разных точек зрения, однако их содержание является общим. Использование языка и понимание оригинального произведения в понимании Мао Дунь - это факторы, которые могут повлиять на пригодность перевода, как это определял Го Можо. Их идеи о критике перевода оказали определяющее влияние на практику литературного перевода и способствовали развитию литературного перевода в Китае.

\section{3. Различия во взглядах на перевод}

Подходы Го Можо и Мао Дуня к переводу во многом определились их представлениями о литературе в целом. Так, Го Можо выступал за «искусство ради искусства», подчеркивая художественную природу литературных произведений, субъективность и индивидуальность. При выборе произведений для перевода он руководствовался в основном художественной ценностью самих произведений, которые могли найти отклик в его сердце и заставить его почувствовать истинное значение искусства. Го Можо перевел целый ряд произведений романтической литературы Германии, Франции и других стран. В свою очередь Мао Дунь выступал за литературу для жизни, с акцентом на объективность и заботу о реальности, и большинство его переводов были реалистичными.

1) Взаимосвязь между переводом и творчеством. Помимо того, что литературный перевод является взаимодействием между двумя разными языками, он также связан с идейно-художественными качествами произведения, которые необходимо выразить, а также зависит от эстетических ориентаций переводчика, социального контекста и национальной культуры обеих сторон (оригинал-перевод). Литературный перевод - это своего рода эстетическая воссоздающая деятельность, преобразование на уровне языка [谢天振 2004,1$]$. Поэтому вопрос о том, как подходить к созданию и переводу литературы, становится для переводчиков актуальным при осуществлении переводческой деятельности. Среди переводчиков возникли различные мнения о том, как 
сбалансировать перевод и творчество. Между Го Можо и Мао Дунем проходили соответствующие дискуссии по вопросу перевода.

В конце династии Цин и начале династии Мин отличительной чертой переводов была их очевидная утилитарность. Либо потому что нужно было зарабатывать на жизнь, либо по другим причинам, переводчики в основном старались угодить вкусам своих читателей, меняя формулировки и даже фразы оригинального текста по своему усмотрению, и лишь немногие из них переводили ради того, чтобы сделать хороший перевод иностранной литературы. Некоторые люди считают, что перевод - это просто копирование, и что писателю нельзя опускаться до переводчика. Однако Мао Дунь всегда активно занимался литературным переводом, лично знакомился со многими иностранными писателями и литературой [廖七一 2010,9]. Го Можо предложил придерживался другой точки зрения, утверждая, что литературный перевод - это искусство само по себе, со своей ценностью и смыслом, и если зацикливаться на социально-утилитарных аспектах перевода, то можно упустить из виду саму суть литературного перевода. Он рассматривал перевод как средство и инструмент творчества и утверждал, что интеллектуалы делают слишком большой акцент на инструментальной роли литературного перевода, что приводит к потере его литературной и художественной ценности. В 1921 г. Мао Дунь утверждал, что по-настоящему изысканный перевод менее ценен, чем творческая работа; а по-настоящему изысканный перевод вдвое труднее, чем творческая работа. Также он считал, что перевод также труден или даже более труден чем сочинительство. Во-первых, для того чтобы перевести произведение, необходимо понять идеи автора; недостаточно по-настоящему оценить художественную красоту оригинала; недостаточно самому войти в оригинальное произведение; надо плакать и смеяться вместе с героями. Во-вторых, используя литературные приемы своего национального языка переводчик должен передать стиль оригинала. Очевидно, что Мао Дунь не был согласен с теорией перевода Го Можо. Он указывает не только на культурное значение перевода, но и на художественную ценность процесса перевода, которая не меньше, чем у творческой работы. Мао Дунь считал, что хороший перевод не только не уступает творческому произведению, но даже превосходит его, поэтому всегда настаивал на важности перевода и сам переводил многие произведения. Взгляды Го Можо на перевод со временем поменялись, так как в результате он пришел к мнению, что перевести стихотворение - это все равно что создать его заново. То есть после собственной переводческой практики он по-другому стал воспринимать связь между литературным творчеством и переводом. Го Можо стал считать, что между переводом и литературным творчеством нет никакой разницы. Осуществить хороший перевод произведения - это непростая задача, и более того, хороший перевод может превзойти оригинал. То есть сначала в период Движения 4 мая Го Можо утверждал, что если сделать слишком большой упор на переводе в ущерб творчеству, то перевод будет в основном поверхностным и литература растворится в переводе. Но в 1954 г. Го Можо уже писал, что перевод - это творческая работа, и хороший перевод равен творческой работе, а может и превосходить ее. И более того, утверждал, что переводческая работа может быть много сложнее, чем создание литературного произведения. Он признает трудности перевода и подчеркивает важность «эмпатии» переводчика к автору оригинала, 
переживания жизни автора оригинала и использования собственного творчества для лучшего перевода. Однако в действительности и перевод, и творчество относятся к сфере литературного искусства, и оба связаны с литературой как часть и целое. Они не являются двумя противоположными сторонами, но в определенной степени могут быть объединены.

Идея Мао Дуня о придании равного значения переводу и сочинительству была своевременной для сдерживания распространения ошибочных представлений о характере перевода иностранной литературы. Первоначальные идеи Го Можо можно считать диаметрально противоположными идеям Мао Дуня, но затем Го Можо перешел на позиции своего коллеги. Перевод и литературное творчество необходимы во все времена, и оба играют свою роль в продвижении дела литературы.

2) O переводе поэзии. Поэзия, как сокровище нации, отражает социальную жизнь и духовный мир народа. Перевод поэзии - это один из важнейших способов развития культурного обмена между разными народами. Го Можо и Мао Дунь также осуществляли перевод поэзии и сформулировали ряд важных теоретических положений по данному вопросу. В этой сфере Го Можо наиболее известен своими переводами стихов английского поэта Шелли (Percy Bysshe Shelley, 1792-1822). В кратком предисловии к «Избранным стихотворениям Шелли» Го Можо, в частности, говорит, что он любит Шелли, слышит его сердцем, резонирует с ним, един с ним, а его стихи похожи на его, и потому он переводит стихи Шелли так, как будто он сам их сочинил [罗新璋 2015, 405]. Это знаменитая 《теория резонанса». Го Можо считает, что переводчик должен настолько глубоко изучить и понять автора оригинала, чтобы стать с ним единым целым, как один человек, а затем своей рукой сделать творческий перевод. Что касается метода поэтического перевода, то Го Можо предложил метод «изящного перевода», который заключается в передаче ритма оригинального стихотворения на основе слова и смысла, а не просто прямого перевода. Наконец, акцент Го Можо на переводе поэзии поэзией является основным различием со взглядами Мао Дуня [罗新璋 2015, 561]. Рифма является характерной чертой поэзии, и если в процессе перевода уничтожается эта рифма, то переведенное произведение не может называться поэзией. Го Можо не ограничивает понимание перевода поэзии буквализмом, а поднимается до эстетического уровня ритма поэзии. Метод же перевода поэзии Мао Дуня сводится к пересказу поэзии. Прежде всего, смысл стихотворения должен быть переведен без произвольных изъятий из оригинала; во-вторых, необходимо сохранить очарование оригинального стихотворения и не изменять самонадеянно его стиль; оригинальный пафос стихотворения должен быть сохранен в переводе. Мао Дунь, в отличие от перевода поэзии поэзией Го Можо, выступал за использование прозы для перевода поэзии. Если стремиться к сохранению оригинальной рифмы, то это будет мешать переводу стихотворения [罗新璋 2015, 420]. Различия между идеями Го Можо и Мао Дуня о переводе в основном отражаются в понимании отношения между переводом и творчеством, а также во взглядах на перевод поэзии - это вопросы, которые и сегодня постоянно обсуждаются в переводческом сообществе Китая. Помимо двух вышеупомянутых аспектов, Мао Дунь также проводил четкое различие между пословным и дословным переводом. То, что Мао Дунь считает дословным переводом, - это не дословный перевод, а перевод, который не предполагает 
изменения слов оригинального произведения и сохраняет настроение и стиль оригинала, передавая его очарование. Напротив, он утверждает, что так как синтаксические структуры китайского и западного языка различны, то пословный перевод является не дословным, а пословным. Это выражение Мао Дуня четко и основательно выражает его взгляд на дословный и пословный перевод.

\section{4. Выводы}

XX век стал важным периодом расцвета китайского переводоведения, поэтому нельзя недооценивать роль, которую сыграли различные переводческие идеи и дебаты в эту эпоху. Го Можо и Мао Дунь, видные китайские писатели и переводчики XX века, сформулировали важные идеи относительно перевода на основе своей личной переводческой практики. Го Можо и Мао Дунь высоко ценили и выдвигали высокие требования к качеству перевода. Кроме того, они оба активно способствовали улучшению качества переводов и развитию переводческой критики в Китае, считая повторный перевод литературных произведений крайне необходимым. Проведенный анализ показывает эволюцию взглядов на перевод Го Можо, особенно что касается поэтического перевода. В целом, сравнительный анализ переводческих идей Го Можо и Мао Дуня показывает, что их идеи схожи, и оба они внесли важный вклад в развитие китайской теории перевода. Сравнительный анализ их переводческих идей дает понимание ситуации в переводческом сообществе и основных переводческих идей в Китае в XX веке, что также оказывает влияние и на дальнейшее развитие китайской теории перевода.

\section{ЛИТЕРАТУРА}

李红英。茅盾的文学翻译思想。社会科学论坛。2008。№ 11。页 127-129。

罗新璋, 陈应年。谈文学翻译工作. 翻译论集. 北京: 商务印书馆, 2015。1048页。

谢天振、查明建。中国现代翻译文学史。上海：上海外语教育出版 社，2004年。669页。

廖七一。中国近代翻译思想的嬗变 - 五四前后文学翻译规范研究。天津: 南开大学出版社，2010年，第9、195页，总321页。

王秉钦. 近现代中国翻译思想史。上海：华东师范大学出版社，2017年，总 292页。

\section{REFERENCES}

Li Hongying (2008), Maodun de wenxue fanyi sixiang, Shehui kexue luntan, № 11, Ye 127-129. (In Chinese).

Luo Xinzhang, Chen Yingnian (2015), Tan wenxue fanyi gongzuo. Fanyi lun ji, Shangwu yin shuguan, Beijing. (In Chinese).

Xie Tianzhen, Cha Mingjian (2004), Zhongguo xiandai fanyi wenxue shi, Shanghai waiyu jiaoyu chubanshe, Shanghai. (In Chinese).

Liao Qiyi (2010), Zhongguo jindai fanyi sixiang de shanbian-wusi qianhou wenxue fanyi guifan yanjiu, Nankai daxue chubanshe, Tianjin. (In Chinese).

Wang Bingqin (2017), Jin xiandai zhongguo fanyi sixiang shi, Huadong shifan daxue chubanshe, Shanghai. (In Chinese). 